\title{
Fine-scale velocity distribution revealed by datuming of VHR deep-towed seismic data: example of a shallow gas system from the western Black Sea
}

\author{
Colin Florent ${ }^{1}$, Ker Stephan ${ }^{1}$, Marsset Bruno ${ }^{1}$
}

${ }^{1}$ Ifremer, REM-GM, 3 Centre de Brest, BP 70, 29280 Plouzané, France

\begin{abstract}
:
Very High-Resolution (VHR) marine seismic reflection helps to identify and characterize potential geohazards occurring in the upper part $(300 \mathrm{~m})$ of the sub-seafloor. Whereas the lateral and vertical resolutions achieved in shallow water depth $(<200 \mathrm{~m})$ using conventional surface-towed technology are adequate, these resolutions quickly deteriorate at greater water depths. SYSIF (SYstème SIsmique Fond), a multichannel deep-towed seismic system, has been designed to acquire VHR data (frequency bandwidth [220-1050 Hz] and vertical resolution of $0.6 \mathrm{~m}$ ) at great water depths. However, the processing of deep-towed multichannel data is challenging as both the source and receivers are constantly moving with respect to each other according to the towing configuration. We present a new workflow that allows the application of conventional processing algorithms to extended deep-towed seismic datasets. First, a relocation of the source and receivers is necessary to obtain a sufficiently accurate acquisition geometry. Variations along the profile in the depth of the deep-towed system result in a complex geometry where the source and receiver depth vary separately and do not share the same acquisition datum. We designed a dedicated datuming algorithm to shift the source and receivers to the same datum. The procedure thus allows the application of conventional processing algorithms to perform both velocity analysis and depth imaging and therefore allowing access to the full potential of the seismic system. We successfully applied this methodology to deep-towed multichannel data from the western Black Sea. In particular, the derived velocity model highlights shallow gas charged anticline structures with unrivaled resolution.
\end{abstract}




\section{INTRODUCTION}

1 Quantitative characterization of shallow marine sediments combining in situ geotechnical 2 measurements and Very High-Resolution (VHR, frequencies $>200 \mathrm{~Hz}$ ) seismic data is of 3 first interest for assessing marine geohazards such as slope stability, shallow gas or gas hy4 drates (Kvalstad, 2007; Vanneste et al., 2014; Clare et al., 2017; Badhani et al., 2020a). In 5 deep-water environments, 2D VHR seismic acquisitions performed at the sea surface suf6 fer from major limitations such as the recording of out-of-plane reflections due to a large 7 first Fresnel zone and a lack of penetration (Chapman et al., 2002; Ker et al., 2010). To

\section{(1)}

allowing seismic acquisitions close to the seafloor in water depths up to a few kilometers (Ward et al., 2004; Badhani et al., 2020b). The first multichannel deep-towed seismic system called DTAGS (Deep Towed Acoustics and Geophysics System), was developed by the U.S. Naval Research Laboratory (Gettrust et al., 1988) and successfully investigated gas hydrate systems (Rowe and Gettrust, 1993; Wood et al., 2002). More recently, a second multichannel deep-towed seismic system, called SYSIF (SYstème SIsmique de Fond), was developed by Ifremer (Marsset et al., 2014) enabling the acquisition of seismic data with submetric vertical resolution. The efficiency of joint analysis of SYSIF data with in situ measurements (i.e., from core analysis and penetrometer tests) has been demonstrated for thin layer quantification (Ker et al., 2011), slope failures (Ker et al., 2010), pockmarks characterization (Sultan et al., 2010; de Prunelé et al., 2017), and hydrate systems assessment (Sultan et al., 2011).

21 An effective approach to the quantitative characterization of gas-charged layers or hydrate bearing sediments lies in detecting P-wave velocity anomalies (Tóth et al., 2014). 
1 However, processing deep-towed seismic data to perform velocity analysis is challenging 2 due to the particular acquisition geometry (Walia and Hannay, 1999; Marsset et al., 2014).

3 Towing a seismic system at a given altitude over the sea bottom requires constant depth 4 adjustments. Such acquisition at variable depth results in a strong variability in the multi5 channel streamer's shape, unlike VHR surface acquisitions performed on a constant datum 6 (i.e., 1-2 $\mathrm{m}$ below the sea surface).

$7 \quad$ Alternative processing approaches have been developed for DTAGS and SYSIF to build 8 a fine-scale velocity model of the subsurface. For DTAGS, the shape of the streamer is 9 retrieved through a combination of depth measurements and traveltimes using a genetic al10 gorithm (He et al., 2009). The seismic data are then propagated to a flat datum by applying

static corrections via a sliding window accounting for the change of raypaths with increasing depth. The process thus allows the application of conventional processing algorithms based on normal moveout (NMO) corrections for velocity analysis (Walia and Hannay, 1999; He et al., 2009). However, the use of static corrections can affect the coherency of acoustic data, especially in a VHR context, and thus acoustic velocity estimations. For SYSIF, a different strategy based on local pitch measurements along the streamer was developed to reconstruct its shape and access the positions of the receivers (Marsset et al., 2014). Then, a migration velocity analysis (MVA) using a Kirchhoff migration technique was implemented to build a velocity model (Marsset et al., 2018). The MVA technique is based on layer stripping and thus requires a large amount of time and computational effort to process a single profile. The algorithm requires computing traveltime maps using an eikonal solver (Podvin and Lecomte, 1990) to update the velocity model for each source/receivers positions and each investigated velocity value. Prestack depth migrations are finally performed to form Common Image Gathers (CIGs). Consequently, the NMO technique appears more 
1 suited, as a first step, to perform an initial comprehensive velocity characterization of an 4 seismic profiles.

extended survey. Such large dataset was acquired by SYSIF in the western Black Sea in $650 \mathrm{~m}$ water depth during the GHASS cruise (Ker and Riboulot, 2015) with 30 deep-towed

To enable the use of a NMO analysis, the seismic data have to be corrected to simulate an acquisition at a constant datum. For this purpose and to avoid the approximations involved in the use of static corrections, we propose a new procedure which applies a waveequation datuming (Berryhill, 1979) to deep-towed seismic data. This technique provides an improvement in deep-towed seismic data processing, as it does not require any assumption regarding the sediment velocity and also preserves the wavefield characteristics. The main difficulties in adapting standard seismic techniques for deep-tow seismic imaging lie in reconstructing very accurately the streamer's shape which varies along the profile, and dealing with the asymmetry of the acquisition geometry where source and receivers do not share the same datum. The first part of this paper addresses the positioning processing and datuming of the data. Once the sources and receivers' depth variations have been corrected to a common datum, the seismic data can then be sorted in Common Midpoint (CMP) gathers, enabling a NMO-based velocity analysis. In the second part, we present the finescale velocity distribution obtained by applying a semblance analysis on a seismic line of the data set. We assess the velocity uncertainty and we quantify the impact of the altitude on the analysis. These results enable to delineate and characterize gas-charged layers and free gas migration paths in the shallow sub-seafloor $(<50 \mathrm{~m})$ with a resolution impossible to obtain from surface-towed seismic systems. 


\section{SYSIF ACQUISITION}

\section{System description}

2 SYSIF is a deep-towed multichannel VHR seismic acquisition system specifically developed 3 by Ifremer to operate down to water depths of $6000 \mathrm{~m}$. The embedded JH220-6000 source is 4 an open cavity Janus-Helmholtz transducer producing a $100 \mathrm{~ms}$ linear frequency-modulated 5 signal $[220-1050 \mathrm{~Hz}]$ with an output level of $196 \mathrm{~dB}$ reference $1 \mu \mathrm{Pa}$ at $1 \mathrm{~m}$ (Le Gall and 6 Marsset, 2007; Ker et al., 2010). The tow-fish is equipped with a pressure sensor for depth 7 measurement and an altimeter for altitude measurement; its location relative to the ship is 8 provided by an acoustic ultra-short base line (USBL) (Marsset et al., 2014).

A 110 m multichannel streamer developed for deep-water acquisitions is towed behind the source. It is composed of 52 digital hydrophones with a $2 \mathrm{~m}$ spacing (first offset 8 m). Each receiver is coupled to a microelectromechanical system (MEMS) to measure its orientation (pitch, roll and yaw angles) during the acquisition. In addition to orientation measurements, the electronic boards embedded in the hydrophones perform the digital conversion of the seismic data $(10 \mathrm{kHz})$ after band-pass filtering [150-3000 Hz]. The data are transmitted to the ship through an optical cable using Ethernet protocol. For design consideration, the streamer is composed of four independent sections including 13 receivers and two Ethernet switches each.

During seismic acquisition, the source is towed at a constant altitude above the seafloor, between $50 \mathrm{~m}$ and $130 \mathrm{~m}$. The altitude choice is a trade off between the safety of the system (i.e. safe altitude above large variations in the bathymetry) and the imaging aperture (i.e., proximity with the target). The source is towed at $1 \mathrm{~m} / \mathrm{s}$ and fired every $2-3 \mathrm{~s}$. The time interval between two shots is chosen carefully before the acquisition to ensure that no 
1 multiple reflection from the previous recording window is present in the active one (Marsset 2 et al., 2014).

\section{Absolute source location}

4 The altitude of the tow-fish is measured by a Kongsberg 1007 altimeter, with a resolution 5 of $0.15 \mathrm{~m}$. A Digiquartz 8CB7000 depth sensor provides the immersion of the tow-fish; its 6 accuracy is $0.01 \%$ full scale, or $0.7 \mathrm{~m}$. The altitude and immersion values are combined to 7 produce a bathymetric profile of the acquisition.

8

The water velocity is obtained from several eXpendable Conductivity-TemperatureDepth (xCTD) vertical profiles down to the maximum depth of the study area (around $1000 \mathrm{~m}$ ) with a maximum uncertainty of $0.15 \mathrm{~m} / \mathrm{s}$. No lateral variation of the seawater velocity have been observed from the three xCTD profiles acquired in the area. The absolute location of the system is validated by comparing the tow-fish bathymetry and the one acquired by the ship multibeam echosounder extracted at the USBL positions.

\section{Signal processing}

Due to the proximity of the system to the seafloor, the $100 \mathrm{~ms}$ length of the sweep causes the overlapping of the direct and reflected wave signals. A specific processing step based on a short term Fourier transform is applied to isolate the two signals and to mute the direct wave (Marsset et al., 2018).

The acoustic sweep source signal requires further processing such as deconvolving to produce a narrow wavelet, consistent with the VHR approach of the system. The far-field source signature was recorded during a previous cruise, which allows the deconvolution of 
1 the data to obtain a narrow, zero-phase wavelet (Ker et al., 2010).

\section{Acquisition parameters of the GHASS survey}

3 Data acquired during the GHASS cruise in the Romanian sector of the Black Sea in 2015

4 are used as a case study in order to demonstrate these new techniques. SYSIF was de-

5 ployed during the cruise to record more than $370 \mathrm{~km}$ of deep-towed VHR seismic lines.

6 Profile PL03PR06 was selected to illustrate the proposed processing workflow. The profile

7 is composed of 1863 shots for a total length of approximatively $5000 \mathrm{~m}$; the shot spacing

8 is $2.7 \mathrm{~m}$ on average. The water depth averages $660 \mathrm{~m}$ and the source was towed $50 \mathrm{~m}$

9 above seafloor. Two sub-profiles are presented: PL03PR06 $\alpha$ (shot points 667 to 917) and

10 PL03PR06 $\beta$ (shot points 667 to 1863 ). The average water velocity is $\mathrm{c}=1482 \mathrm{~m} / \mathrm{s}$ at the

11 depth of the sub-profiles and shows no evidence of lateral variation.

\section{VARIABLE ARRAY SHAPE}

12 An excellent knowledge of the acquisition geometry is essential for the processing of VHR

13 data as inaccuracies will cause destructive summation and reduce dramatically the resolu-

tion. This loss in resolution is first evaluated; a relocation procedure is then presented to retrieve the variable array geometry.

\section{Impact of the geometry on imaging performance}

We first quantify the resolution capacity of the VHR deep-towed system. This quantification is achieved by assessing the size of the focusing pattern related to the migration of a diffraction point. Vertical and lateral resolutions are obtained by measuring respectively the 
trough-to-trough vertical width (Kallweit and Wood, 1982) and the horizontal full width at half-maximum (de Souza, 2014) of the migration pattern. It should be noted that the horizontal resolution value represents the maximum resolution, as the horizontal resolution then decreases with depth.

We simulate the acquisition of a diffraction point embedded in a homogeneous medium using the far-field signature of the Janus-Helmholtz transducer (220-1050 Hz). We model the acquisition of a single shot gather where the diffraction point is located $50 \mathrm{~m}$ below the source and at a lateral position of $56 \mathrm{~m}$ behind the source. The streamer's shape is defined as horizontal. Kirchhoff migration is applied to the shot gather using the exact velocity and a $10 \mathrm{~cm}$ bin size. Using the exact geometry, this results in a horizontal resolution of $1.5 \mathrm{~m}$ and a vertical resolution of $0.6 \mathrm{~m}$.

To define the resolution loss associated to receivers' position errors, constant Gaussian noise is added to the receivers' position with a standard deviation $\sigma_{\text {noise }}$, multiple values were used from $0.05 \mathrm{~m}$ to $0.8 \mathrm{~m}$. We perform the forward modeling and the migration of the shot gather for 2000 simulations of the Gaussian process to evaluate the degradation of both resolutions for each $\sigma_{\text {noise }}$. The progressive loss of resolution with increasing $\sigma_{\text {noise }}$ is presented in Figure 1. These results allows us to estimate the expected loss of resolution after determining the accuracy of the relocation algorithm.

\section{Navigation data processing}

The depth variations of the tow-fish propagate along the streamer similar to an elastic wave. This fluctuating geometry causes changes in the source-receiver's offsets. MEMS sensors located inside each hydrophone record the pitch and heading angles to determine 
1 the streamer's shape and thus the receiver's location (Marsset et al., 2014, 2018). In the 2 acquisition area, deep sea currents are expected to reach on average $0.05 \mathrm{~m} / \mathrm{s}$ and no more 3 than $0.20 \mathrm{~m} / \mathrm{s}$ (Korotaev et al., 2006; Markova et al., 2016). Given that the acquisition is 4 conducted much faster, at $1 \mathrm{~m} / \mathrm{s}$ on average, no significant feathering is expected to affect 5 the streamer. Therefore, the shape of the streamer is reconstructed by only using pitch 6 measurements.

7 The raw pitch values are corrected from sensor bias, filtered and integrated along the $8 \quad$ streamer to obtain the vertical and horizontal offsets $x_{r}^{i}$ and $z_{r}^{i}$ of each receiver ("the MEMS 9 geometry") as follows:

$$
\left\{\begin{array}{l}
x_{r}^{i}=x_{0}+\int_{0}^{r^{i}} \cos [\alpha(r)] d r \\
z_{r}^{i}=\int_{0}^{r^{i}} \sin [\alpha(r)] d r
\end{array}\right.
$$

where $r^{i}$ is the curvilinear abscissa of the $i^{\text {th }}$ receiver from the head of the streamer and $\alpha$ the pitch angle at position $r$ down the streamer. The curvilinear distance between two receivers is $2 \mathrm{~m}$. The curvilinear distances between the head of the streamer and the $1^{\text {st }}$ and $52^{n d}$ receivers are respectively $8 \mathrm{~m}$ and $110 \mathrm{~m}$. The additional $x_{0}=2.1 \mathrm{~m}$ in horizontal offset corresponds to the distance between the acoustic barycenter of the transducer and the towing point of the streamer (Figure 2).

The accuracy of this reconstruction is evaluated by comparing traveltimes of the direct wave arrivals and the acoustic wave reflected at the seafloor picked on seismic data $t_{o b s}^{i}$ with the computed values $t_{\text {calc }}^{i}(\alpha)$ expressed as: 


$$
t_{\text {calc }}^{i}(\alpha)=\left\{\begin{array}{l}
t_{\text {dir }}^{i}=d_{\text {dir }}^{i} \cdot c^{-1} \\
t_{\text {floor }}^{i}=d_{\text {floor }}^{i} \cdot c^{-1},
\end{array}\right.
$$

1 with

$$
d_{d i r}^{i}=\sqrt{\left(x_{r}^{i}\right)^{2}+\left(z_{r}^{i}\right)^{2}}
$$

2 and

$$
d_{\text {floor }}^{i}=\sqrt{\left(x_{\text {floor }}^{i}\right)^{2}+\left(z_{\text {floor }}^{i}\right)^{2}}+\sqrt{\left(x_{r}^{i}-x_{\text {floor }}^{i}\right)^{2}+\left(z_{r}^{i}+z_{\text {floor }}^{i}\right)^{2}},
$$

3

4 receiver, $d_{\text {floor }}^{i}$ and $t_{\text {floor }}^{i}$ the distance and traveltime of the seafloor reflected wave to the $5 i^{t h}$ receiver, $x_{\text {floor }}^{i}$ is the horizontal distance between the $i^{\text {th }}$ receiver and the reflection 6 point on the seafloor for the reflected wave reaching the $i^{t h}$ receiver, $z_{\text {floor }}^{i}$ is the vertical 7 distance between the $i^{t h}$ receiver and the seafloor at the reflection point. Note that $x_{\text {floor }}^{i}$ 8 and $z_{\text {floor }}^{i}$ vary with the known bathymetry of the area, the vertical and horizontal offsets

where $d_{d i r}^{i}$ and $t_{d i r}^{i}$ are the direct distance and traveltime from the source to the $i^{t h}$ of the receiver and the altitude of the source. Figure 2 presents the different parameters of equations 2-4.

Values of picked and computed traveltimes and their differences are presented in Figure 3 for a given shot record. The average around $0.8 \mathrm{~ms}$ error corresponds to an error of about $1.2 \mathrm{~m}$ in the position of the receivers (for a constant water velocity of $1482 \mathrm{~m} / \mathrm{s}$, measured by xCTD probes). Marsset et al. (2018) apply a static shift to reduce this discrepancy and obtained time misfits ranging from $0.1 \mathrm{~ms}$ to $0.7 \mathrm{~ms}$. If this correction improves the quality of the data summation, it also introduces errors in retrieving P-wave velocity values. We propose a new approach to avoid the former issue and reduce the positioning uncertainties. The method aims to retrieve an accurate acquisition geometry based on the inversion of the seismic arrival times to refine pitch angle values used in the streamer shape reconstruction. 


\section{Array shape reconstruction}

2 To retrieve the streamer shape, the traveltimes misfits between the observed and computed 3 values using equation 2 are computed using the least-squares method. The cost function 4 for the relocation inverse problem is defined as:

$$
S=\min _{\alpha(r)} \sum_{i}\left\{t_{c a l c}^{i}\left[\alpha\left(r^{i}\right)\right]-t_{o b s}^{i}\right\}^{2}
$$

5

6

The relocation inverse problem consists in finding 53 pitch angles values (i.e., one value per receiver and an additional one at the connection between the tow-fish and the lead-in cable) from 104 traveltime observations. A curvilinear spacing of $2 \mathrm{~m}$ between two consecutive receivers and a smooth shape variation of the streamer also constrain the inversion. We employ a local optimization method (the trust region approach, Byrd et al., 1988) to solve this inverse problem, and we use the MEMS pitch angles as initial values to start the search for the minimum value of $\mathrm{S}$.

While preserving the general trend of the pitch values measured by the MEMS (Figure 4a), the inversion retrieves a sine-like event in the streamer shape with a series of peaks and troughs (Figure 4b). The troughs correspond to the positions of the Ethernet switches, which are embedded in titanium containers and have a mass of $1.3 \mathrm{~kg}$. The streamer is neutrally buoyant as a whole, but these denser components (Figure 4b, black dots) cause the streamer to be locally denser than seawater, which causes local deformations of the streamer.

The mean time misfit for the direct wave and the seafloor reflected wave are around 0.18 ms and $0.10 \mathrm{~ms}$, respectively (Figure 5, green curve). An increased time misfit toward the 
1 tail of the streamer can be observed on both traveltimes in Figures 5a and 5b. The average

time misfit for the seafloor reflected wave increases to $0.25 \mathrm{~ms}$ for the last ten receivers in comparison to less than $0.1 \mathrm{~ms}$ for the first 30. This increasing misfit can be related to several factors such as a larger uncertainty in picked arrival times, a less constrained streamer tail or a uncounted for streaming feathering.

These results translate to positioning uncertainties of $0.27 \mathrm{~m}$ and $0.15 \mathrm{~m}$ respectively, that correspond to a maximum loss of resolution of about $8 \%$ (Figure 1). This loss in resolution decreases the theoretical vertical resolution to $0.65 \mathrm{~m}$ and the maximum horizontal resolution to $1.62 \mathrm{~m}$, for a homogeneous medium and an exact velocity model.

The results of the relocation procedure are evaluated with the comparison of the profile PL03PR06 $\alpha$, from the GHASS cruise, processed using the initial MEMS geometry and the one obtained after correction. Figure 6 displays both images obtained after a Kirchhoff pre-stack depth migration (PSDM) using a constant velocity model of $1482 \mathrm{~m} / \mathrm{s}$.

\section{WAVE-EQUATION DATUMING}

Complex acquisition geometries can be found in UHR shallow-towed seismic acquisitions where the swell can affect the positions of the sources and receivers. However, swell-related motions are limited to a couple of meters and can be corrected with the application of statics corrections (Duarte et al., 2017; Reiche et al., 2020). In the case of deep-towed multichannel acquisitions, the vertical offsets can vary up to several tens of meters and the horizontal offset up to several meters. These large variations prove to be an issue for the processing of deep-towed data as conventional marine seismic imaging algorithms are usually tailored for data presenting only small depth variations of the sources and receivers, usually neglected 
1 or corrected accurately enough with statics corrections. An analogy for such a geometry 2 can be found in land seismic acquisition, where the altitude of the sources and receivers can 3 differ greatly. Therefore, the processing of land seismic data commonly includes a datuming 4 phase, i.e. the sources and receivers are moved to a constant altitude.

$5 \quad$ One elementary way to perform datuming is to apply small static corrections to travel6 times in the simplest cases to correct for altitude deviations, e.g. small deviations from the 7 reference altitude and low ray-paths emergence angles (Barison et al., 2011). However, for 8 significant topographic variations, an exact wavefield propagation is necessary to accurately 9 upward or downward continue the data to a reference datum. This action of correcting the 10 acquisition datum by wavefield continuation is called wave-equation datuming (WED) and 11 was first introduced by Berryhill (1979).

The acoustic signal recorded at a single receiver can emerge from various angles. Therefore, if we were to propagate the wave to a distinct datum, different time corrections would be needed depending on the emergence angles. Based on this observation, Berryhill proposed a Kirchhoff integral formulation for his wave-equation datuming to propagate the seismic data to a reference datum while preserving the wavefield character of the data (Berryhill, 1979, 1984, 1986).

\section{Theory of wave-equation datuming}

For non-zero offset data, the Kirchhoff integral is applied in two successive stages (Bevc, 1996). The following notation is used in the description of the algorithm:

- "input" traces: the original traces. The acoustic signals are emitted at the acquisition source positions and recorded at the acquisition receiver positions $\left(x_{r}, z_{r}\right)$, 
7

- "intermediate" traces: the traces after the first stage of processing. The signals are emitted at the acquisition source positions and recorded at the datumed receiver positions,

- "datumed" trace: the traces at the output of the algorithm. The signals emitted at the datumed source positions and recorded at the datumed receiver positions.

The first stage consists in moving the receivers from their acquisition positions to the selected datum by summing the input traces $P$ to intermediate traces $p$ as follows:

$$
p_{j}=\sum_{i=-M}^{M} A_{i j} \frac{\partial^{1 / 2}}{\partial t^{1 / 2}} P_{i}\left(t-\tau_{i j}\right)
$$

shere $\tau_{i j}$ is the traveltime between the acquisition receiver location $i$ and the datumed receiver location $j$ and $M$ defines the limit of the contributing receivers located on either side of the datumed receiver. Notice that $M$ is to be determined based on the maximum geological dip present and the maximum elevation change between the acquisition geometry and the final datum. In equation $6, A_{i j}$ is an amplitude correction term based on spherical divergence and obliquity:

$$
A_{i j}=\frac{\Delta x}{2 \pi r_{i j} v} \cos \left(\theta_{i j}\right)
$$

14 where $v$ is the datuming velocity, $\Delta x$ represents the spatial sampling interval, and $\theta_{i j}$ is the angle between the normal to the input surface and the raypath path $r_{i j}$ connecting the acquisition receiver $i$ location and the datumed receiver $j$ location (Bevc, 1995).

In the second stage of the algorithm, the sources are moved from their acquisition positions to the datum by summing the intermediate traces $p$ to the final datumed traces 


$$
P_{k}^{\prime}=\sum_{j=-N}^{N} A_{j k} \frac{\partial^{1 / 2}}{\partial t^{1 / 2}} p_{j}\left(t-\tau_{j k}\right)
$$

2

3

4 and 5 and $\theta_{j k}$ is the corresponding angle.

6

7 (with receivers on both sides of the source) to treat equally the layers dipping in either

where $N$ defines the limits of the contributing traces, based on the positions of the sources located on either side of the datumed source, $A_{j k}$ is defined according to equation 7 and the $r_{j k}$ factor defines the distance between the acquisition and datumed source locations,

An important aspect raised by Berryhill is the need of a split-spread acquisition geometry direction. Split-spread geometries are the standard in land acquisitions but not in marine surveys. Berryhill advises making use of the reciprocity between sources and receivers to circumvent this issue. Reciprocity states that, for a given seismic trace, interchanging the positions of the source and the receiver will result in an identical signal, assuming that both source and receiver have no directivity (Clærbout, 1976). Berryhill (1984) assumes that the streamer and the source share a common datum, thus reciprocity can be used to design an artificial split-spread geometry.

In the case of a SYSIF acquisition, the depth of the tow-fish is constantly adjusted according to the bathymetry to maintain a constant altitude). As a result, the source depth is varying and the receiver offset are fluctuating along the seismic line. They do not share a common datum, thus reciprocity cannot be used to create a split spread configuration. Therefore, the WED procedure has to be altered for deep-towed acquisition geometry. 


\section{Adaptation of WED to deep-towed data}

2 The adaptation of the WED algorithm to deep-tow data aims at correcting the vertical 3 variations of the source's positions and the vertical and horizontal variations of the receivers' 4 positions relative to the source. These variations are caused by the deformations of the 5 streamer following the motion of the tow-fish. The inability to use reciprocity to form a 6 split-spread configuration prevents the straightforward application of the WED to SYSIF 7 data. Nonetheless, our implementation of the datuming follows the same main steps:

1. definition of the reference datum and of the datumed system geometry,

2. moving the receivers to the reference datum: equation 6 is applied to the input data sorted in the Common Shot Gather (CSG) domain,

3. moving the shot positions to the reference datum: equation 8 is applied to the intermediate data sorted in the Common Receiver Gather (CRG) domain,

4. time-variant muting, to avoid angle extrapolations caused by the datuming, is applied on the data sorted in the CMP domain.

We now review these four steps.

\section{Step 1: defining the datumed geometry}

The reference datum is chosen higher (upward continuation) than the shallowest receiver or source position of the profile to avoid the datum crossing any velocity interface (i.e., the seafloor). We subtract $5.0 \mathrm{~m}$ from the shallowest position to ensure that there is no null, or close to zero, denominator in the amplitude correction factor (equation 7). As 
1 the acquisition positions and the common datum are located above the seafloor, seawater 2 velocity is used to convert the distances to times.

3

4 given depth. The angle content drives the accuracy for later velocity analysis and therefore 5 needs to be preserved during the datuming procedure. The depth and dip of the reflector,

6 the length of the streamer and the velocity field, define the maximum emergence angle of a 7 raypath. The largest angle recorded by the system for a shot is marked as $\theta_{\max }$ in Figure $87 \mathrm{a}$, it corresponds to the reflection on the seafloor measured at the last receiver.

The WED moves the acquisition system to a reference datum that is higher, hence further away from the target. To compensate for this higher altitude and to preserve the angle content of the data, the length of the datumed streamer length is increased (Figure 7a). We calculate for each shot, the vertical shift $\Delta z_{52}$ between the last $\left(52^{n d}\right)$ receiver's acquisition position and the datum. The prolongation of the ray defined by $\theta_{\max }$ to the reference datum indicates the position of the last datumed receiver. This position can be calculated:

$$
x_{\max }^{\prime}=x_{52}+\Delta z_{52} \tan \left(\theta_{\max }\right)
$$

where $x_{\text {max }}^{\prime}$ is the offset of the last datumed receiver and $x_{52}$ is the horizontal offset of the last receiver.

We selected a datumed receiver spacing of $1 \mathrm{~m}$, half that of the acquisition spacing, as it interpolates the data in the angle domain. The longitudinal offset between the source and the first receiver causes a blind spot in the data in the angle domain. This blind spot is reproduced in the datumed data by offsetting the position of the first virtual receiver 
1 (Figure 7a). With the first and last receiver offsets known and the receiver spacing defined, the number of virtual receivers $n_{r}^{\prime}$ is calculated.

\section{Step 2: moving the receivers}

4 The second step of the procedure consists of relocating the receivers from their acquisition 5 positions to the reference datum. The data are sorted in the CSG domain and each CSG is 6 processed individually. The summation described by equation 6 is carried out for each vir7 tual receiver on the reference datum. The contributing input traces are selected depending 8 on the position of the receivers. Initially, the traces are summed between two boundaries $9 \quad-M$ and $M$ (equation 6), yet we cannot use these same boundaries in a deep-tow configuration because of the end-on spread geometry. Instead, we integrate the input traces between a trace 0 and a trace limit $M$. The trace 0 is associated to the input receiver located directly below the datumed receiver $j\left(\theta_{i j}=0^{\circ}\right.$ in equation 7 , marked as "Receiver 0 " in Figure $7 \mathrm{~b})$. The upper bound of summation $M$ corresponds to the trace associated to the input receiver that defines a maximum angle of $\theta_{\max }$ (Figure $7 \mathrm{a}$ ) between the input receiver location and the datumed receiver location, counted positive toward the source (marked as "Receiver M" in Figure 7b). Hence, for a virtual receiver on the reference datum, the contributing input traces are selected if the corresponding receivers lay in a cone defined by a vertical axis and the angle $\theta_{\max }$. The traces are time corrected by the traveltimes $\tau_{i j}$ between the acquisition and datumed receiver positions (Figure $7 \mathrm{~b}$ and equation 6 ). The input traces are corrected in amplitude by the factor $A_{i j}$ described by Bevc (1995) in equation 7. Finally, the selected traces are summed to form the intermediate trace $p_{j}$.

The number of datumed receivers is increased from the native 52 to a number dependent 
1 on the vertical shift. The sources remain located at their acquisition positions.

\section{Step 3: moving the sources}

3 In this third step, we move the sources from their acquisition locations to the reference 4 datum. To that purpose, we need to reorganize the intermediate traces from the CSG domain into the CRG domain. To sort the data as CRGs, we divide the seismic profile in 6 bins; each CRG is composed of the traces where the receiver's location falls into a given 7 bin. The bins are $1 \mathrm{~m}$ wide to ensure the CRGs contain a large enough number of traces.

By taking advantage of reciprocity to virtually invert the positions of the sources and receivers, we can observe that the geometry of the CRG is similar to that of an acquisition shot point as showed in Figure 7c. To preserve the angle content of the data, the length of the streamer (actually composed of shot points) is increased according to the CRG's maximum angle of reflection $\theta_{\text {max }}^{\prime}$, in a similar way as in Step 2.

The correction of the sources' locations for each CRG is equivalent to the one applied to the receivers. For each datumed source, the contributing traces are selected from the CRG if the acquisition sources' positions lie in the area delimited by the vertical axis (i.e., 0 as lower bound of summation in equation 8) and $\theta_{\max }^{\prime}$ (Figure $7 \mathrm{~d}$ ). The first contributing source is marked as "Source 0" in Figure 7d and the last contributing source is marked as "Source $N^{\prime \prime}$. The selected traces are then time corrected by a factor of $\tau_{j k}$ which corresponds to the distance between the acquisition sources' locations and the datumed source's position (Figure 7c). The amplitudes of the traces are corrected by the factor $A_{j k}$ (equation 7 ). The corrected traces are finally summed to form the datumed trace $P^{\prime}$.

At the end of this third step, the sources and receivers are now located at their final 
1 positions on the reference datum. The data set now consists of single-track data with a 2 wide variety of offsets.

\section{Step 4: time-variant muting}

4 An important aspect of the wave-equation datuming is to preserve the angle range, which 5 means that reflection angles associated to the datumed geometry cannot be higher than 6 the ones acquired by the deep-towed system. As the maximum offset of the new datum 7 geometry is defined by considering the maximum reflected angle at the seafloor, for deeper 8 reflectors, the datuming procedure may extrapolate data and generate higher reflection

$$
\begin{aligned}
& \text { for } t>T, P_{k}^{\prime}(t)=0, \\
& \text { where } T=\frac{x_{r}^{\prime k}}{V \sin \left[\theta_{\max }(t)\right]} .
\end{aligned}
$$

$\theta_{\max }(t)$ is evaluated from the acquisition source and receiver positions considering a homogeneous medium with a constant velocity $V$ and a lithology parallel to the seafloor. The constant velocity $V$ is set equal to the seawater velocity $c$ as the depth velocity profile is unknown at this stage of the data processing. Although the different lithological layers constituting the subsurface may refract the wavefield depending on their respective velocities 
1 and geometries, we consider our computation of $\theta_{\max }(t)$ accurate enough to perform the 2 time-variant mute. The reflection angles are calculated by marching a $1 \mathrm{~m}$ window repeat3 edly from the seafloor down to the maximum imaged depth. A muted CMP is depicted in 4 Figure 8. A comparison between two common-offset sections, before and after datuming, is 5 presented in the Supplementary material.

\section{VHR VELOCITY ANALYSIS}

6 The datuming of the deep-towed seismic data allows the sorting of the traces into CMP 7 gathers and performing the velocity analysis using a standard NMO method. We first 8 illustrate some results obtained from the deep-towed data acquired at the altitude of $50 \mathrm{~m}$ 9 during the GHASS cruise. Nevertheless, during the cruise most acquisitions were performed 10 at an altitude of $100 \mathrm{~m}$ above seafloor for safety considerations. In that configuration, the

angular content of the data is narrower, thus limiting the precision of the velocity analysis.

Therefore, we investigate the impact of the altitude of the system on velocity determination.

Finally, we use the velocity field to perform a prestack depth migration revealing very fine details of the shallow gas system.

\section{Semblance analysis}

We perform the velocity analysis every $10 \mathrm{~m}$ by forming $5 \mathrm{~m}$ wide super-gathers. The velocity analysis is performed by computing the semblance spectrum (Al-Chalabi, 1979). Computations are performed with a temporal step of $1 \mathrm{~ms}$, and a velocity step of $1 \mathrm{~m} / \mathrm{s}$. The NMO velocity profile associated to a super-gather is determined by picking the maximum semblance values. To insure the lateral continuity of the picking from consecutive semblance 
1 panels, the semblance maxima are picked following notable reflectors where possible. The 2 NMO velocity is then assimilated to the root mean square $(\mathrm{rms})$ velocity $\left(V_{r m s}\right)$ and the 3 interval velocity is computed using the Dix formula (Dix, 1955). The interval velocity 4 uncertainties are estimated using the method developed by Hajnal and Sereda (1981) where 5 the uncertainty is a function of the $V_{r m s}$ and $T_{r m s}$. The uncertainty on the $V_{r m s}$ is given 6 by taking the velocity interval corresponding to $98 \%$ of the picked semblance maximum 7 (Dewangan and Ramprasad, 2007). The time uncertainty on the picking is set constant at

$0.45 \mathrm{~ms}$, which corresponds to the temporal resolution of the system obtained after array shape reconstruction.

The velocity analysis performed on the deep-towed data after datuming is illustrated on Figure 9a where a semblance spectrum computed from CMP X $=2023 \mathrm{~m}$ is presented. The corresponding interval velocity profile converted in depth by calculating the zero-offset depth related to the picked times (Figure 9c). The interval velocity uncertainties increase with depth, which is related to the decrease of the angle range. The velocity estimation on the seafloor is in agreement with the seawater velocity measured using the $\mathrm{xCTD}$ probes, which validates the consistency of the applied workflow. The interval velocity distribution (Figure 9b) displays an anticline structure characterized by a drop in $\mathrm{P}$-wave velocity from $1450 \mathrm{~m} / \mathrm{s}$ to about $1000 \mathrm{~m} / \mathrm{s}$ associated to gas-charged layers.

\section{Impact of the acquisition altitude}

Most profiles acquired during the GHASS cruise were obtained by setting the altitude of SYSIF's tow-fish to $100 \mathrm{~m}$ to ensure the safety of the equipment. To assess the impact of the altitude on interval velocity estimations, a line was acquired twice with two different 
1 altitudes: profiles PL03PR06 (previously presented) and PL01PR11 obtained at altitudes 2 of $50 \mathrm{~m}$ and $100 \mathrm{~m}$, respectively.

3

4 (i.e., datuming and semblance analysis) to the profile PL01PR11. As acquiring data with 5 a deep-towed system remains a challenging positioning task both profiles do not share the 6 exact same location with a maximum difference in lateral positioning of $48 \mathrm{~m}$ between the 7 two profiles. The results are presented in Figure 10. If the semblance is less resolved with 8

larger maxima (Figure 10a) due to the limited range of reflection angles, a rms velocity decrease is observed in relation to the presence of free gas. Interval velocities are similar to with those obtained with an altitude of $50 \mathrm{~m}$, but the uncertainty has doubled. Even with larger uncertainty in velocity estimates, deep-towed seismic data acquired at $100 \mathrm{~m}$ can be used to assess velocity variation trends in the first $70 \mathrm{~m}$ of sediments. In particular, the decrease in velocity related to the presence of free gas within the anticline is unambiguously revealed in both profiles.

\section{Depth imaging of the shallow gas system in great water depth}

The western Black Sea has been a long-term site for investigating the role of fluids in submarine landslides. The presence of numerous mounts (average diameter $80 \mathrm{~m}$, average height $15 \mathrm{~m}$ ), interpreted as inherited morphology resulting from the compressive bulge of a massive landslide have been reported (Riboulot et al., 2017). These mounts were surveyed using high-resolution surface-towed seismic during the GHASS cruise (Ker et al., 2019) but conventional seismic failed to determine their internal structure due to the water depth (650-1000 m) in the area. The deep-towed seismic data presented in this contribution are 
1 the result of a targeted seismic survey over these mounts during the GHASS cruise. The in2 terval velocity distribution obtained after the processing of the profile PL03PR06 $\alpha$ (Figure

9b) was used to perform a prestack depth migration based on a Kirchhoff method detailed in Marsset et al. (2014, 2018). Figure 10 enables a qualitative comparison between the depth migrated profile processed with a constant velocity (Figure 11a) and one processed with the interval velocity distribution (Figure 11c). CIG located at the center of the anticline structure are also presented in Figures $11 \mathrm{~b}$ and d. The accuracy of the interval velocity estimates is demonstrated by the flatness of seismic reflections in CIG (Figure 11d) compared to the constant velocity case (Figure 11b). The resolution of the push-down associated with the presence of free gas illustrates the validity of the velocity model (the push-down is an artifact caused by a local low velocity zone). The maximum vertical shift is $1.6 \mathrm{~m}$, which corrects the positions of the reflectors in depth. This accuracy in the velocity model is due to the improved description of the streamer shape, followed by the wave-equation datuming. Consequently, this workflow proves to be a powerful processing tool allowing the application of conventional algorithms to unconventional seismic data. The processing sequence, including NMO and pre-stack depth migration, can be routinely applied to large data sets as illustrated on Figure 12. The velocity analysis performed on profile PL03PR06 $\beta$ shows three low acoustic velocity areas allowing the identification of three anticline structures filled with gas (Figures 12c-12e).

\section{CONCLUSION}

We demonstrated the performance of the deep-towed multichannel seismic system SYSIF both in terms of imaging capability and velocity characterization. The presented workflow allows the investigation of small-scale structures at great water depth. The processing of 
1 deep-towed data requires a careful reconstruction of the variable streamer shape to make 2 up for the deformations of the deep-towed streamer along the seismic profile. The inversion 3 of the local pitch angles of the streamer based on traveltimes (direct and seafloor reflected) 4 improves the effective resolutions to $1.62 \mathrm{~m}$ (horizontal) and $0.65 \mathrm{~m}$ (vertical), or $92 \%$ that 5 of the theoretical resolutions ( $1.5 \mathrm{~m}$ horizontal, $0.6 \mathrm{~m}$ vertical). A precise knowledge of the 6 receiver locations enables datuming the data set to take advantage of conventional seismic 7 processing algorithms. For extended deep-towed surveys over gently dipping geological $8 \quad$ structures, NMO analysis after datuming provides small-scale velocity models at great water 9 depth. We performed the velocity analysis and the depth imaging of the profile PL03PR06 $\beta$. 10 Three anticline structures, corresponding to the mounts from the western Black Sea, were 11 well identified; all associated with low velocity $(850-1100 \mathrm{~m} / \mathrm{s})$ and high amplitude reflectors.

The velocity analysis allowed to identify velocity changes within structures less than $10 \mathrm{~m}$ thick and less than $50 \mathrm{~m}$ wide. The joint interpretation of the velocity distribution and depth image highlighted that free gas has migrated from a deeper source and has been trapped in anticline structures preventing it to reach the seafloor. Fine-scale push-down effects $(<2 \mathrm{~m})$ within these anticline structures were successfully resolved when performing velocity analysis and depth imaging at $650 \mathrm{~m}$ water depth. The accuracy in the final velocity distribution is, by definition, related to the angle content of the seismic data. Therefore, the quality of the acquired seismic data is a trade-off between safety considerations and the optimal acquisition altitude. The presented algorithms applied to the GHASS deeptowed data proved a mean of taking full advantage of the deep-towed multichannel seismic technology that brings a unique insight to the characterization of geohazards taking place at great water depths. 


\section{ACKNOWLEDGMENTS}

1 The support by officers and crew during the GHASS cruise on board R/V Pourquoi Pas? 2 (2015) is greatly appreciated, as is the dedication of the Genavir and Ifremer technical staff 3 during the cruise. We thank Mark Noble and an anonymous reviewer for their comments 4 that helped us to improve this paper. We thank Yannick Thomas and Shane Murphy for 5 insightful discussions. 


\section{REFERENCES}

1 Al-Chalabi, M., 1979, Velocity determination from seismic reflection data, in Developments

2 in Geophysical Exploration Methods-1, applied science publishers ed.: Springer, 1-68.

3 Badhani, S., A. Cattaneo, S. Collico, R. Urgeles, B. Dennielou, E. Leroux, F. Colin, S.

4 Garziglia, M. Rabineau, and L. Droz, 2020a, Integrated geophysical, sedimentological

5 and geotechnical investigation of submarine landslides in the Gulf of Lions (Western

6 Mediterranean): Geological Society, London, Special Publications, SP500-2019-175.

7 Badhani, S., A. Cattaneo, B. Dennielou, E. Leroux, F. Colin, Y. Thomas, G. Jouet, M.

8 Rabineau, and L. Droz, 2020b, Morphology of retrogressive failures in the Eastern Rhone

$9 \quad$ interfluve during the last glacial maximum (Gulf of Lions, Western Mediterranean): Geomorphology, 351, 106894.

Barison, E., G. Brancatelli, R. Nicolich, F. Accaino, M. Giustiniani, and U. Tinivella, 2011, Wave equation datuming applied to marine OBS data and to land high resolution seismic profiling: Journal of Applied Geophysics, 73, 267-277.

Berryhill, J. R., 1979, Wave-equation datuming: Geophysics, 44, 1329-1344.

— 1984, Wave-equation datuming before stack: Geophysics, 49, 397-399.

— 1986, Submarine canyons: Velocity replacement by wave-equation datuming before stack: Geophysics, 51, 1572-1579.

Bevc, D., 1995, Imaging under rugged topography and complex velocity structure: $\mathrm{PhD}$ thesis, Stanford University.

- 1996, Flooding the topography: Wave-equation datuming of land data with rugged acquisition topography: Geophysics, 62, 1558-1569.

Byrd, R. H., R. B. Schnabel, and G. A. Shultz, 1988, Approximate solution of the trust region problem by minimization over two-dimensional subspaces: Mathematical Program- 
ming, 40, 247-263.

Chapman, N. R., J. F. Gettrust, R. Walia, D. Hannay, G. D. Spence, W. T. Wood, and R. D. Hyndman, 2002, High-resolution, deep-towed, multichannel seismic survey of deepsea gas hydrates off western Canada: Geophysics, 67, 1038-1047.

Clærbout, J. F., 1976, Fundamentals of geophysical data processing: With applications to petroleum prospecting: Blackwell Scientific Publications.

Clare, M. A., M. E. Vardy, M. J. B. Cartigny, P. J. Talling, M. D. Himsworth, J. K. Dix, J. M. Harris, R. J. S. Whitehouse, and M. Belal, 2017, Direct monitoring of active geohazards: Emerging geophysical tools for deep-water assessments: Near Surface Geophysics, 15, $427-444$.

de Prunelé, A., L. Ruffine, V. Riboulot, C. A. Peters, C. Croguennec, V. Guyader, T. Pape, C. Bollinger, G. Bayon, J.-C. Caprais, Y. Germain, J.-P. Donval, T. Marsset, G. Bohrmann, L. Géli, A. Rabiu, M. Lescanne, E. Cauquil, and N. Sultan, 2017, Focused hydrocarbon-migration in shallow sediments of a pockmark cluster in the Niger Delta (Off Nigeria): Geochemistry, Geophysics, Geosystems, 18, 93-112.

de Souza, J. L., 2014, A Method to Estimate Spatial Resolution in 2-D Seismic Surface Wave Tomographic Problems: International Journal of Geosciences, 05, 757-770.

Dewangan, P., and T. Ramprasad, 2007, Velocity and AVO analysis for the investigation of gas hydrate along a profile in the western continental margin of India: Marine Geophysical Researches, 28, 201-211.

Dix, C. H., 1955, Seismic velocities from surface measurements: Geophysics, 20, 68-86.

Duarte, H., N. Wardell, and O. Monrigal, 2017, Advanced processing for UHR3D shallow marine seismic surveys: Near Surface Geophysics, 15, 347-358.

Gettrust, J. F., M. Grimm, S. Madosik, and M. Rowe, 1988, Results of a deep-tow multi- 
$1 \quad$ channel survey on the Bermuda Rise: Geophysical Research Letters, 15, 1413-1416.

Hajnal, Z., and I. T. Sereda, 1981, Maximum uncertainty of interval velocity estimates: Geophysics, 46, 1543-1547.

He, T., G. D. Spence, W. T. Wood, M. Riedel, and R. D. Hyndman, 2009, Imaging a hydrate-related cold vent offshore Vancouver Island from deep-towed multichannel seismic data: Geophysics, 74 (2), B23-B36.

Kallweit, R., and L. C. Wood, 1982, The limits of resolution of zero-phase wavelets: Geophysics, 47, 1035-1046.

Ker, S., Y. Le Gonidec, D. Gibert, and B. Marsset, 2011, Multiscale seismic attributes: A wavelet-based method and its application to high-resolution seismic and ground truth data: Multiscale seismic attributes: Geophysical Journal International, 187, 1038-1054.

Ker, S., B. Marsset, S. Garziglia, Y. Le Godinec, D. Gibert, M. Voisset, and J. Adamy, 2010, High-resolution seismic imaging in deep sea from a joint deep-towed/OBH reflection experiment: Application to a Mass Transport Complex offshore Nigeria: Geophysical Journal International, 182, 1524-1542.

Ker, S., and V. Riboulot, 2015, GHASS cruise, R/V Pourquoi Pas ?, https://doi.org/10.17600/15000500.

Ker, S., Y. Thomas, V. Riboulot, N. Sultan, C. Bernard, C. Scalabrin, G. Ion, and B. Marsset, 2019, Anomalously deep BSR related to a transient state of the gas hydrate system in the western Black Sea: Geochemistry, Geophysics, Geosystems, 20, 442-459.

Korotaev, G., T. Oguz, and S. Riser, 2006, Intermediate and deep currents of the Black Sea obtained from autonomous profiling floats: Deep Sea Research Part II: Topical Studies in Oceanography, 53, 1901-1910.

Kvalstad, T., 2007, What is the Current "Best Practice" in Offshore Geohazard Investi- 
1 gations? A State-of-the-Art Review: Presented at the Offshore Technology Conference, 2 Offshore Technology Conference.

3 Le Gall, Y., and B. Marsset, 2007, Développements électroacoustiques en sismique marine

4 Très Haute Résolution: Acoustique et Techniques, 17-22.

5 Markova, N., Marine Hydrophysical Institute, Russian Academy of Sciences, A. Bagaev, $6 \quad$ and Marine Hydrophysical Institute, Russian Academy of Sciences, 2016, The Black Sea

7 Deep Current Velocities Estimated from the Data of Argo Profiling Floats: Physical $8 \quad$ Oceanography.

9 Marsset, B., S. Ker, Y. Thomas, and F. Colin, 2018, Deep-towed high-resolution seismic 10 imaging II: Determination of P-wave velocity distribution: Deep-Sea Research Part I, $132,29-36$.

Marsset, B., E. Menut, S. Ker, Y. Thomas, J.-P. Regnault, P. Leon, H. Martinossi, L. Artzner, D. Chenot, S. Dentrecolas, B. Spychalski, G. Mellier, and N. Sultan, 2014, Deep-towed high-resolution multichannel seismic imaging: Deep Sea Research I, 93, 8390.

Podvin, P., and I. Lecomte, 1990, Finite difference computation of traveltimes in very contrasted velocity models: A massively parallel approach and its associated tools: Geophysical Journal International, 418, 271-284.

Reiche, S., B. Berkels, and B. Weiß, 2020, Automated static and moveout corrections of high-resolution seismic data from the Baltic Sea: Near Surface Geophysics, 18, 23-37.

Riboulot, V., A. Cattaneo, C. Scalabrin, A. Gaillot, G. Jouet, G. Ballas, T. Marsset, S. Garziglia, and S. Ker, 2017, Control of the geomorphology and gas hydrate extent on widespread gas emissions offshore Romania: Bulletin de la Société géologique de France, $188,26$. 
1 Rowe, M. M., and J. F. Gettrust, 1993, Fine structure of methane hydrate-bearing sediments on the Blake Outer Ridge as determined from deep-tow multichannel seismic data: Journal of Geophysical Research: Solid Earth, 98, 463-473.

Sultan, N., B. Marsset, S. Ker, T. Marsset, M. Voisset, A. M. Vernant, G. Bayon, E. Cauquil, J. Adamy, J. L. Colliat, and D. Drapeau, 2010, Hydrate dissolution as a potential mechanism for pockmark formation in the Niger delta: Journal of Geophysical Research, $115,1-33$.

Sultan, N., V. Riboulot, S. Ker, B. Marsset, L. Géli, J. B. Tary, F. Klingelhoefer, M. Voisset, V. Lanfumey, J. L. Colliat, J. Adamy, and S. Grimaud, 2011, Dynamics of fault-fluid-hydrate system around a shale-cored anticline in deepwater Nigeria: Journal of Geophysical Research, 116, B12110.

Tóth, Z., V. Spiess, J. M. Mogollón, and J. B. Jensen, 2014, Estimating the free gas content in Baltic Sea sediments using compressional wave velocity from marine seismic data: Journal of Geophysical Research: Solid Earth, 119, 8577-8593.

Vanneste, M., N. Sultan, S. Garziglia, C. F. Forsberg, and J.-S. L'Heureux, 2014, Seafloor instabilities and sediment deformation processes: The need for integrated, multidisciplinary investigations: Marine Geology, 352, 183-214.

Walia, R., and D. Hannay, 1999, Source and receiver geometry corrections for deep towed multichannel seismic data: Geophysical Research Letters, 26, 1993-1996.

Ward, P., E. Asakawa, and S. Shimizu, 2004, High Resolution, Deep-Tow Seismic Survey to Investigate the Methane Hydrate Stability Zone in the Nankai Trough: Resource Geology, 54, 115-124.

Wood, W. T., J. F. Gettrust, N. R. Chapman, G. D. Spence, and R. D. Hyndman, 2002, Decreased stability of methane hydrates in marine sediments owing to phase-boundary 
1

2

3

4

5

6

7

8

10

1

군 2

3

4

ป1 5

96

\%

8

019

82
82
021

हुㄹㄹ

3

25

Q26

尊7

$\frac{91}{3}$

30

31

.32

33

.్రే

35

36

:37

\$9

git0

$-41$

42

政3

S4

-45

46

J47

${ }_{4} 48$

$\frac{3}{4} 9$

क्ष̃ 0

1

๑5

53

54

55

56

57

58

59

60

1 roughness: Nature, 420, 656-660. 


\section{LIST OF FIGURES}

1

$2 \sigma_{\text {noise value. }}$

3

4

$5 d_{\text {floor }}^{i}, z_{\text {floor }}^{i}$ and $x_{\text {floor }}^{i}$ depend on the depth of the source and receiver as well as the slope

6 of the seafloor.

7

2 Description of an average acquisition configuration for the deep-towed multichannel seismic acquisition SYSIF. The tow-fish is not to scale with the streamer. The distances 3 Seafloor reflected wave traveltimes picked on the seismic data and computed using the MEMS streamer's geometry for shot 823. Differences in traveltimes between the picked values and the one computed using the MEMS geometry (red crosses).

4 (a) Measured and inverted pitch values for shot 823 . The inverted pitch value at the 0 abscissa corresponds to the lead-in cable. (b) corresponding MEMS and inverted geometries (vertical exaggeration: 3.0).

5 Average differences between $t_{\text {calc }}$ computed using the MEMS geometry (red curve) or the inverted geometry (green curve) and $t_{o b s}$ for profile PL03PR06 $\alpha$, (a) direct wave and (b) seafloor reflected wave. The vertical lines represent the standard deviation.

6 PL03PR06 $\alpha$ : profiles processed with a PSDM using a constant velocity model. (a) Data processed using the MEMS geometry. (b) Data processed using the inverted geometry (vertical exaggeration: 7.3 ).

7 Representation of the first steps of the wave-equation datuming. (a) definition of the geometry associated with the displacement of the receivers. The largest offset of the datumed receivers is defined by the vertical shift of the last receiver and by the maximum reflection angle $\theta_{\max }$ on the seafloor. (b) selection of the traces stacked to move the receivers to the datum. (c) definition of the geometry associated with the displacement of the sources. 
1 The largest offset is defined by the offset of the last source and by the maximum reflection angle $\theta_{\max }$ on the seafloor. In this example, the traces are gathered as CRG's at the bin $\mathrm{X}=74 \mathrm{~m}$ (bin width $1 \mathrm{~m}$ ). (d) selection of the traces stacked to move the sources to the datum.

8 Datumed, muted traces sorted in the CMP domain. The traces are muted when the associated datumed reflection angles are greater than the acquired $\theta_{\max }(t)$, delimited by the red line. The muting time $T$ is calculated according to the offset $x_{r}^{\prime k}$ (equation 10). 9 PL03PR06a: (a) Semblance panel and picked $V_{r m s}$ velocities at the CMP X = $2023 \mathrm{~m}$. The gray lines represent a $\pm 2 \%$ velocity uncertainty on the semblance picks. (b) interval velocity distribution where dots indicate the position of the picked velocities. (c) interval velocity profile and uncertainties at the CMP X $=2023 \mathrm{~m}$ (represented by the green dashed line in subplot (b).

10 PL01PR11: (a) Semblance panel and picked $V_{r m s}$ velocities at the CMP X $=4508$ m. The gray lines represent a $\pm 2 \%$ amplitude uncertainty on the semblance picks. (b) interval velocity distribution where dots indicate the position of the picked velocities. (c) interval velocity profile and uncertainties at the CMP X $=4508 \mathrm{~m}$ (represented by the green dashed line in subplot (b).

11 (a) Sub-profile PL03PR06 $\alpha$, PSDM migrated. using a constant seawater velocity model. (c) is that same profile migrated using the variable velocity model presented in Figure 9b (vertical exaggeration: 10.0). (b) and (d) show the same CMP located at the center of the anticline structure, marked by the green line, migrated at constant velocity and with the velocity model (respectively).

12 Profile PL03PR06 $\beta$. (a) shows the interval velocity structures. (b) displays the seismic profile migrated using the velocity model presented in (a) (vertical exaggeration: 
$1 \quad 6.25)$. 


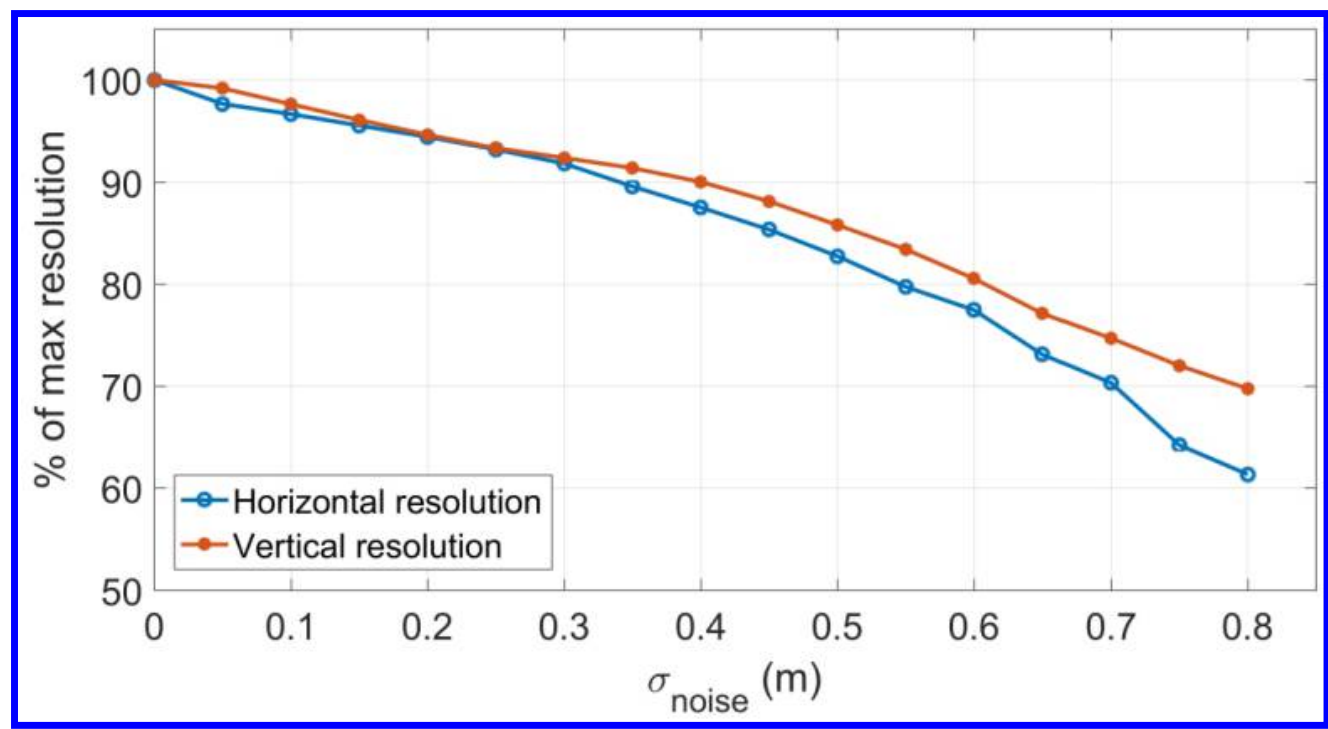

Figure 1 - Loss of horizontal and vertical resolutions as a function of $\sigma_{\text {noise }} 2000$ runs per $\sigma_{\text {noise }}$ value. 


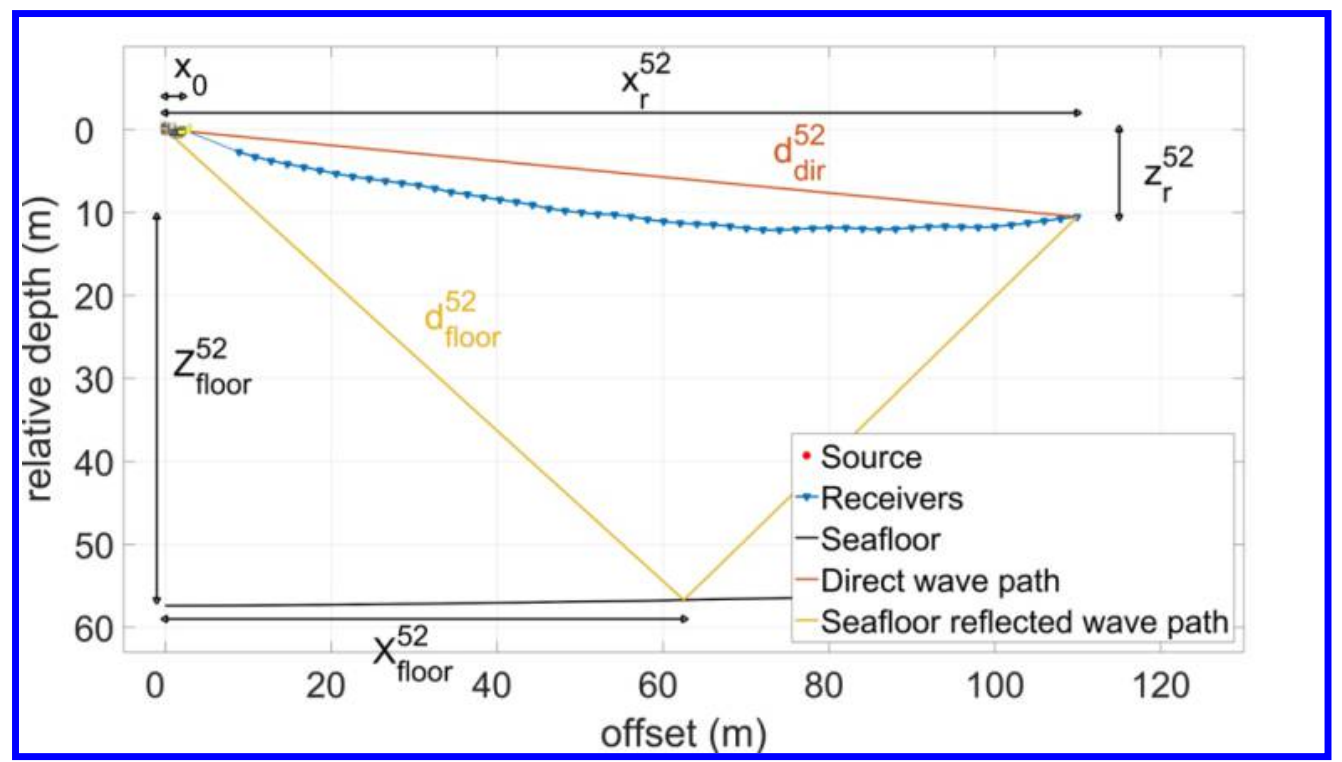

Figure 2 - Description of an average acquisition configuration for the deep-towed multichannel seismic acquisition SYSIF. The tow-fish is not to scale with the streamer. The distances $\mathrm{d}^{\mathrm{i}}$ floor, $\mathrm{z}^{\mathrm{i}}$ floor and $\mathrm{x}^{\mathrm{i}}$ floor depend on the depth of the source and receiver as well as the slope of the seafloor. 


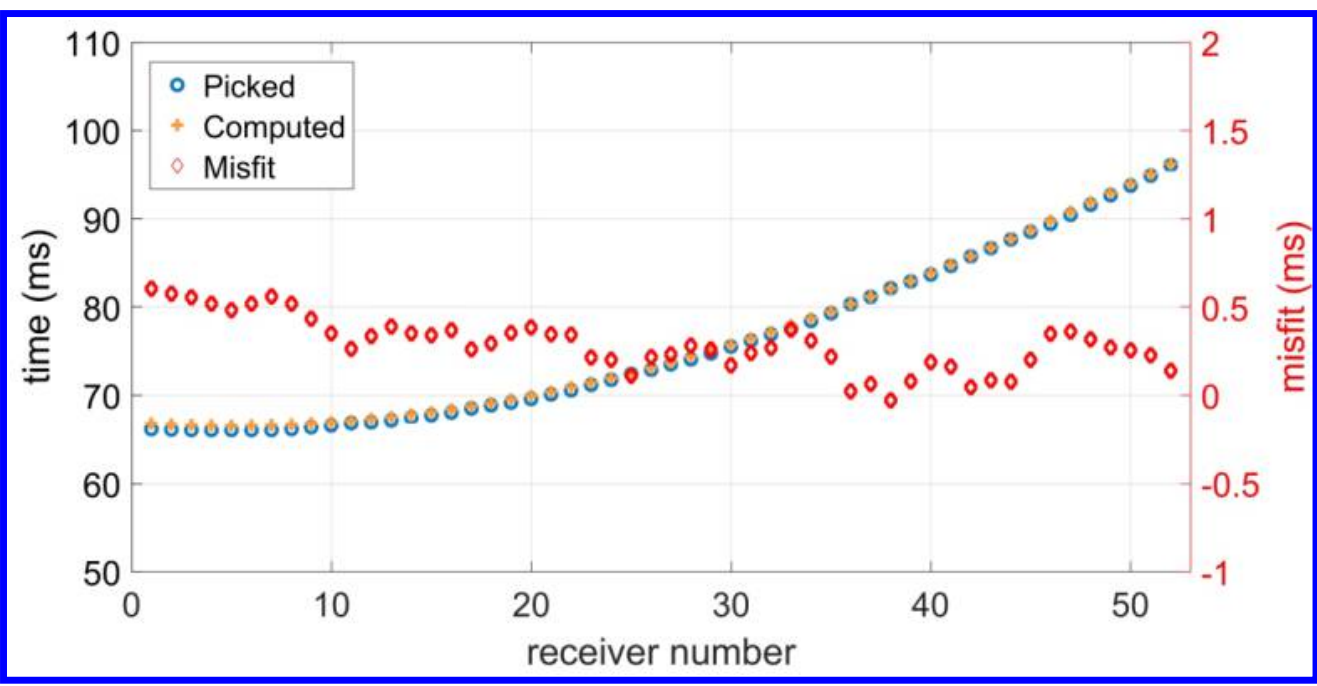

Figure 3 - Seafloor reflected wave travel times picked on the seismic data and computed using the MEMS streamer's geometry for shot 823. Differences in travel times between the picked values and the one computed using the MEMS geometry (red crosses). 


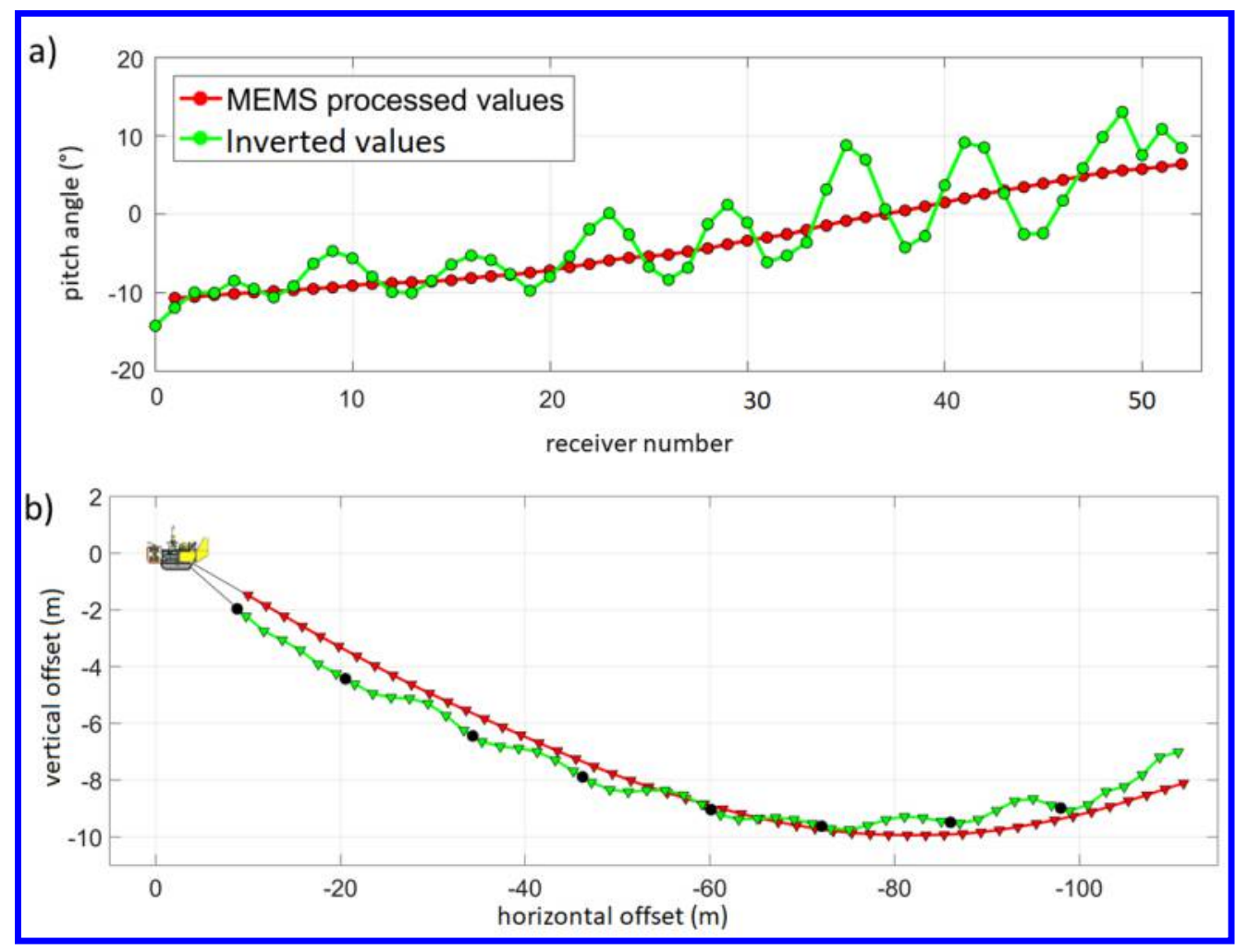

Figure 4 - (a) Measured and inverted pitch values for shot 823 . The inverted pitch value at the 0 abscissa corresponds to the lead-in cable. (b) corresponding MEMS and inverted geometries (vertical exaggeration: 3.0). 


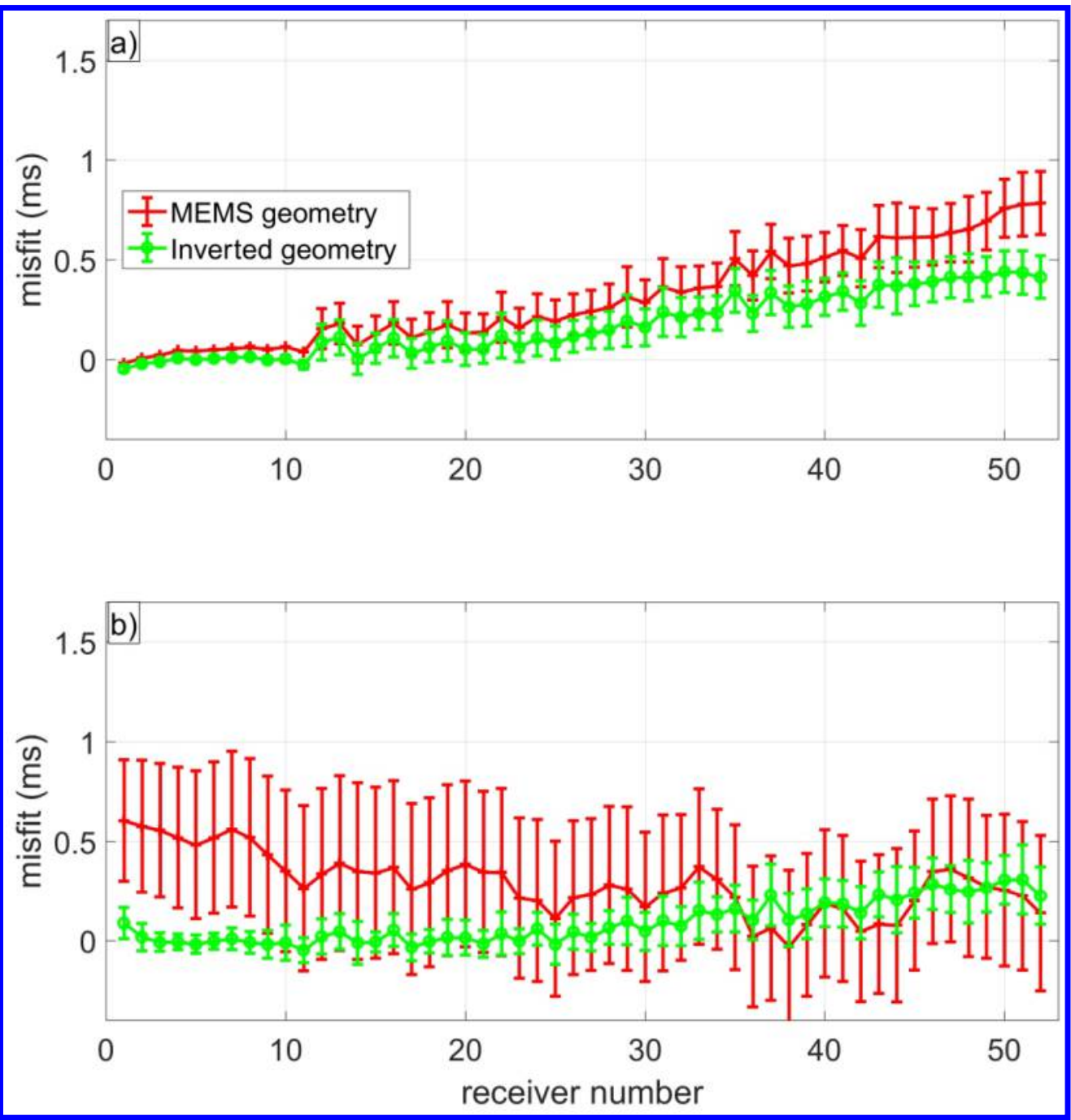

Figure 5 - Average differences between $t_{\text {calc }}$ computed using the MEMS geometry (red curve) or the inverted geometry (green curve) and $t_{\text {obs }}$ for profile PL03PR06a, (a) direct wave and (b) seafloor reflected wave. The vertical lines represent the standard deviation.

This paper presented here as accepted for publication in Geophysics prior to copyediting and composition. (C) 2020 Society of Exploration Geophysicists. 


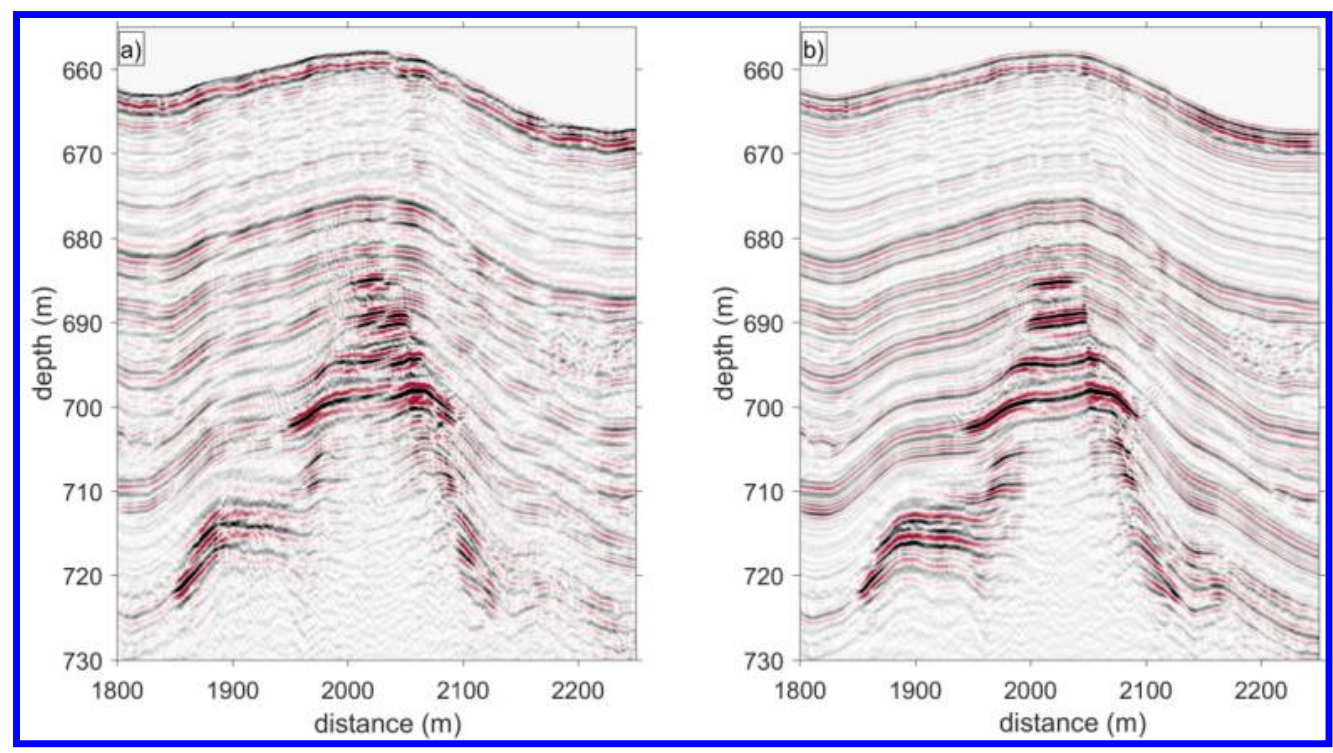

Figure 6 - PL03PR06a: profiles processed with a PSDM using a constant velocity model. (a) Data processed using the MEMS geometry. (b) Data processed using the inverted geometry (vertical exaggeration: 7.3). 


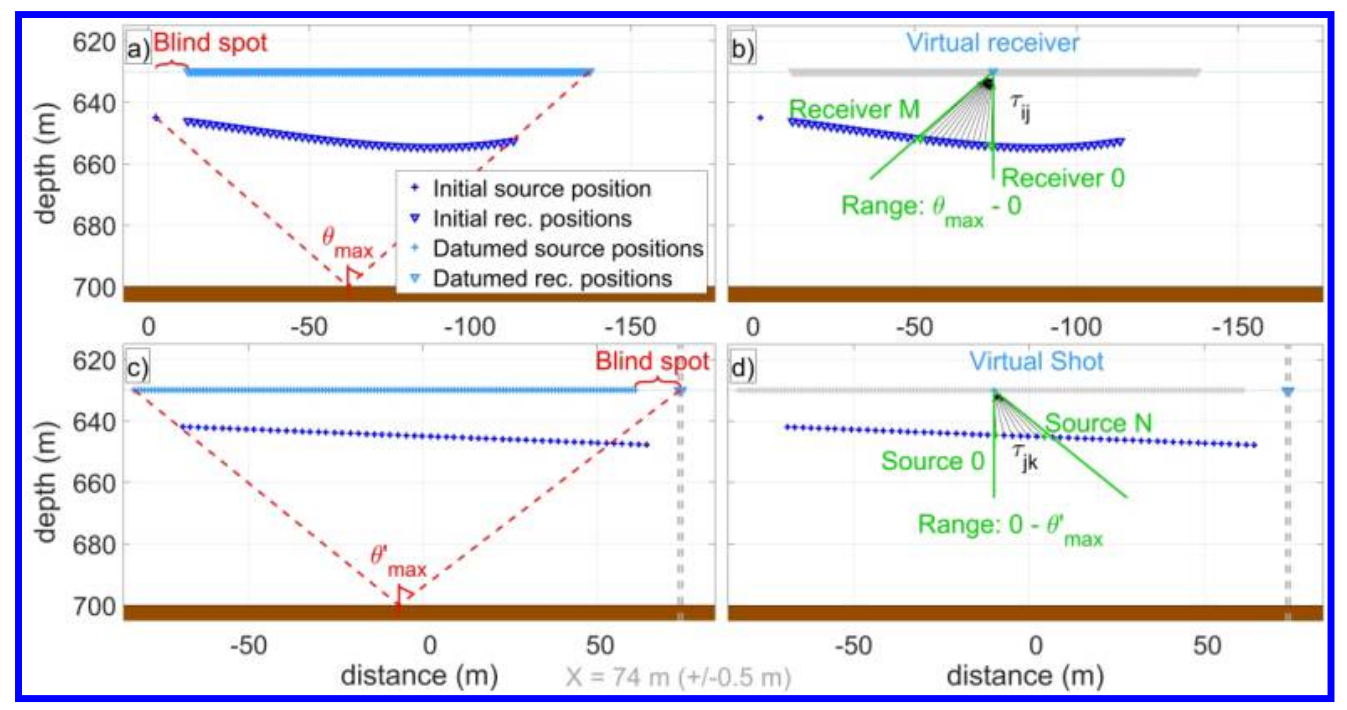

Figure 7 - Representation of the first steps of the wave-equation datuming. (a) definition of the geometry associated with the displacement of the receivers. The largest offset of the datumed receivers is defined by the vertical shift of the last receiver and by the maximum reflection angle $\theta_{\max }$ on the seafloor. (b) selection of the traces stacked to move the receivers to the datum. (c) definition of the geometry associated with the displacement of the sources. The largest offset is defined by the offset of the last source and by the maximum reflection angle $\theta_{\max }$ on the seafloor. In this example, the traces are gathered as CRG's at the bin $X=74 \mathrm{~m}$ (bin width $1 \mathrm{~m}$ ). (d) selection of the traces stacked to move the sources to the datum. 


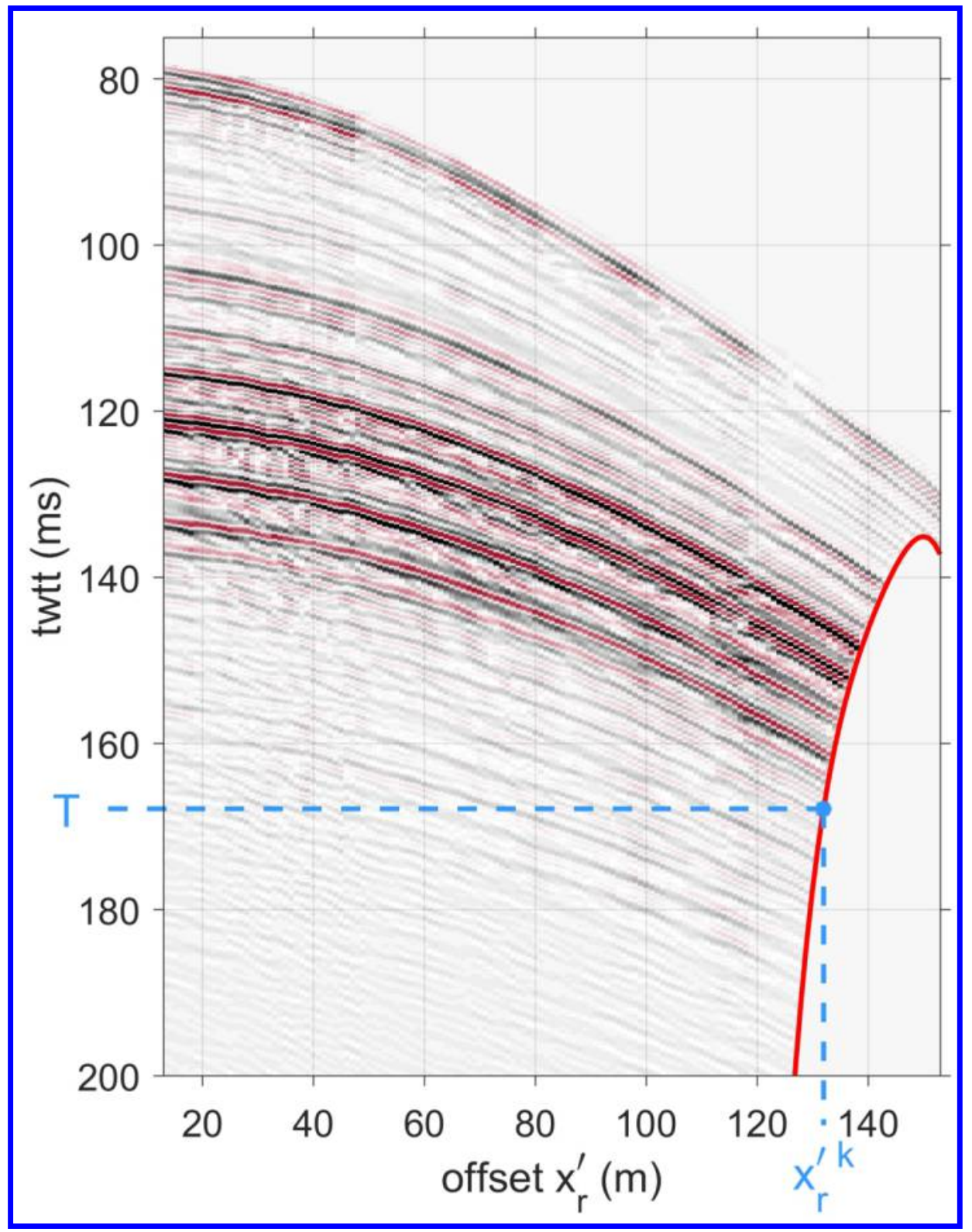

Figure 8 - Datumed, muted traces sorted in the CMP domain. The traces are muted when the associated datumed reflection angles are greater than the acquired $\theta_{\max }(t)$, delimited by the red line. The muting time $T$ is calculated according to the offset $x^{\prime}{ }_{r}{ }^{k}$ (equation 10 ). 


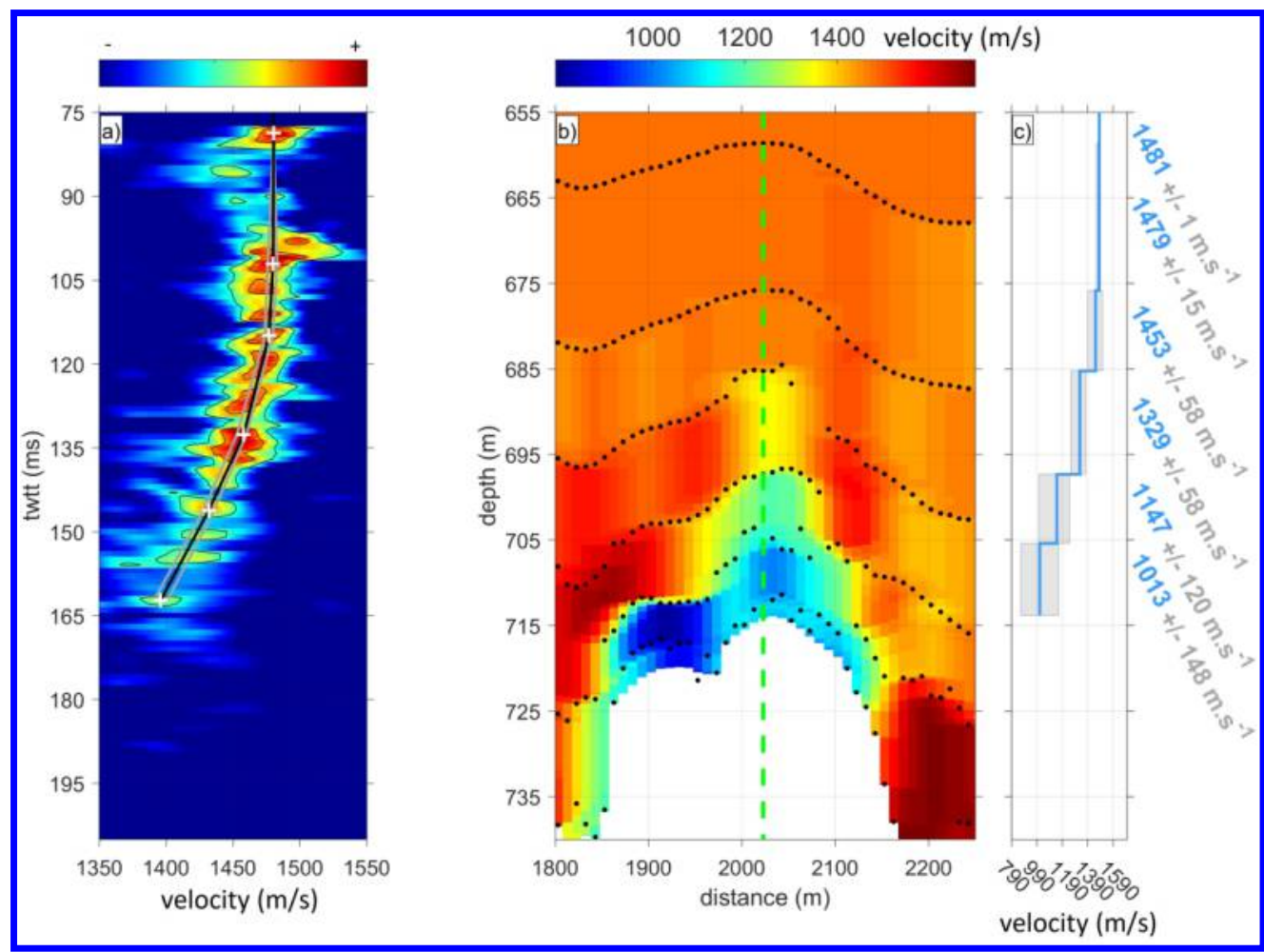

Figure 9 - PL03PR06a: (a) Semblance panel and picked $\mathrm{V}_{\mathrm{rms}}$ velocities at the CMP X $=2023 \mathrm{~m}$. The gray lines represent $a \pm 2 \%$ velocity uncertainty on the semblance picks. (b) interval velocity distribution where dots indicate the position of the picked velocities. (c) interval velocity profile and uncertainties at the CMP X $=2023 \mathrm{~m}$ (represented by the green dashed line in subplot (b). 


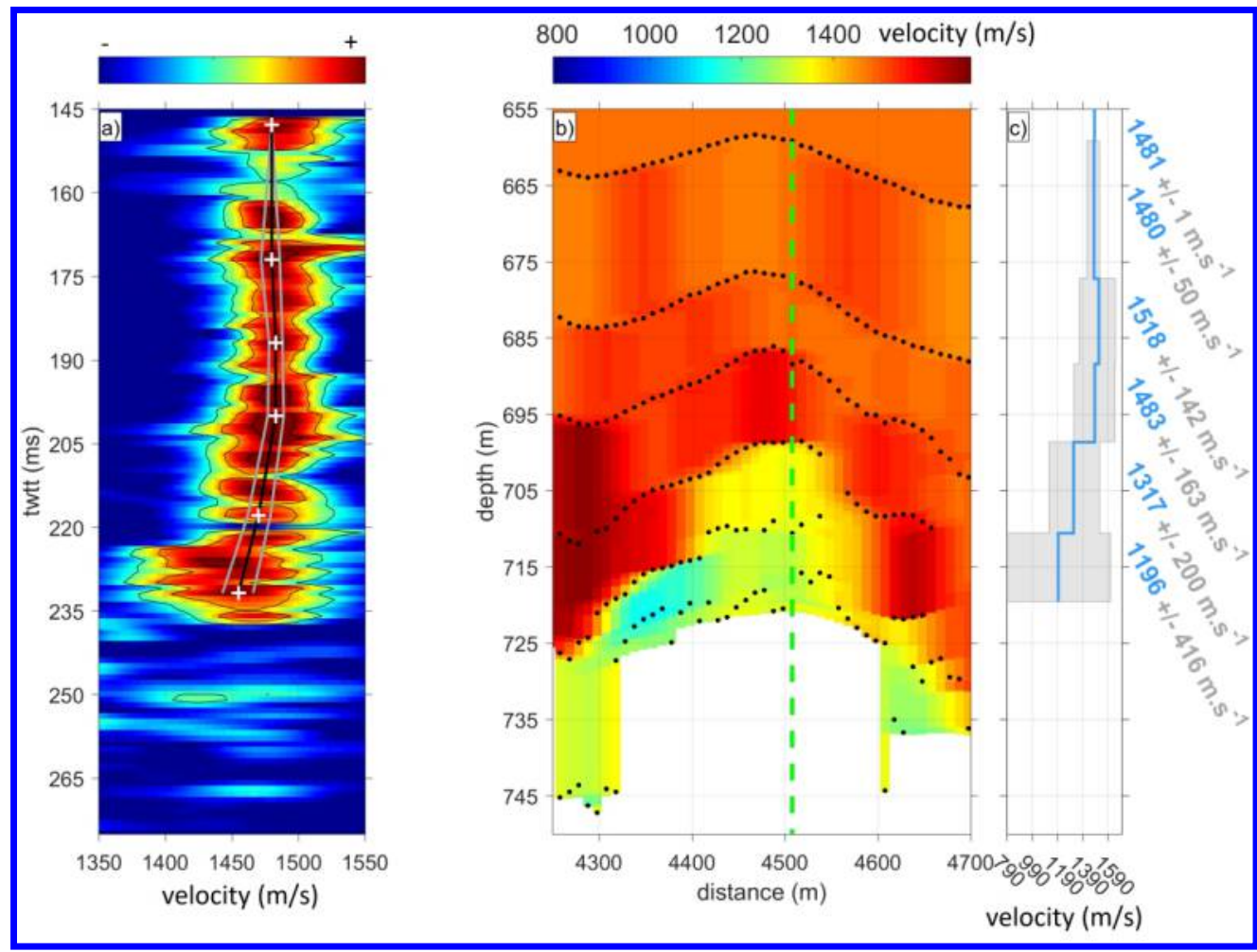

Figure 10 - PL01PR11: (a) Semblance panel and picked $V_{r m s}$ velocities at the CMP X $=4508 \mathrm{~m}$. The gray lines represent $a \pm 2 \%$ amplitude uncertainty on the semblance picks. (b) interval velocity distribution where dots indicate the position of the picked velocities. (c) interval velocity profile and uncertainties at the CMP $X$ $=4508 \mathrm{~m}$ (represented by the green dashed line in subplot (b). 

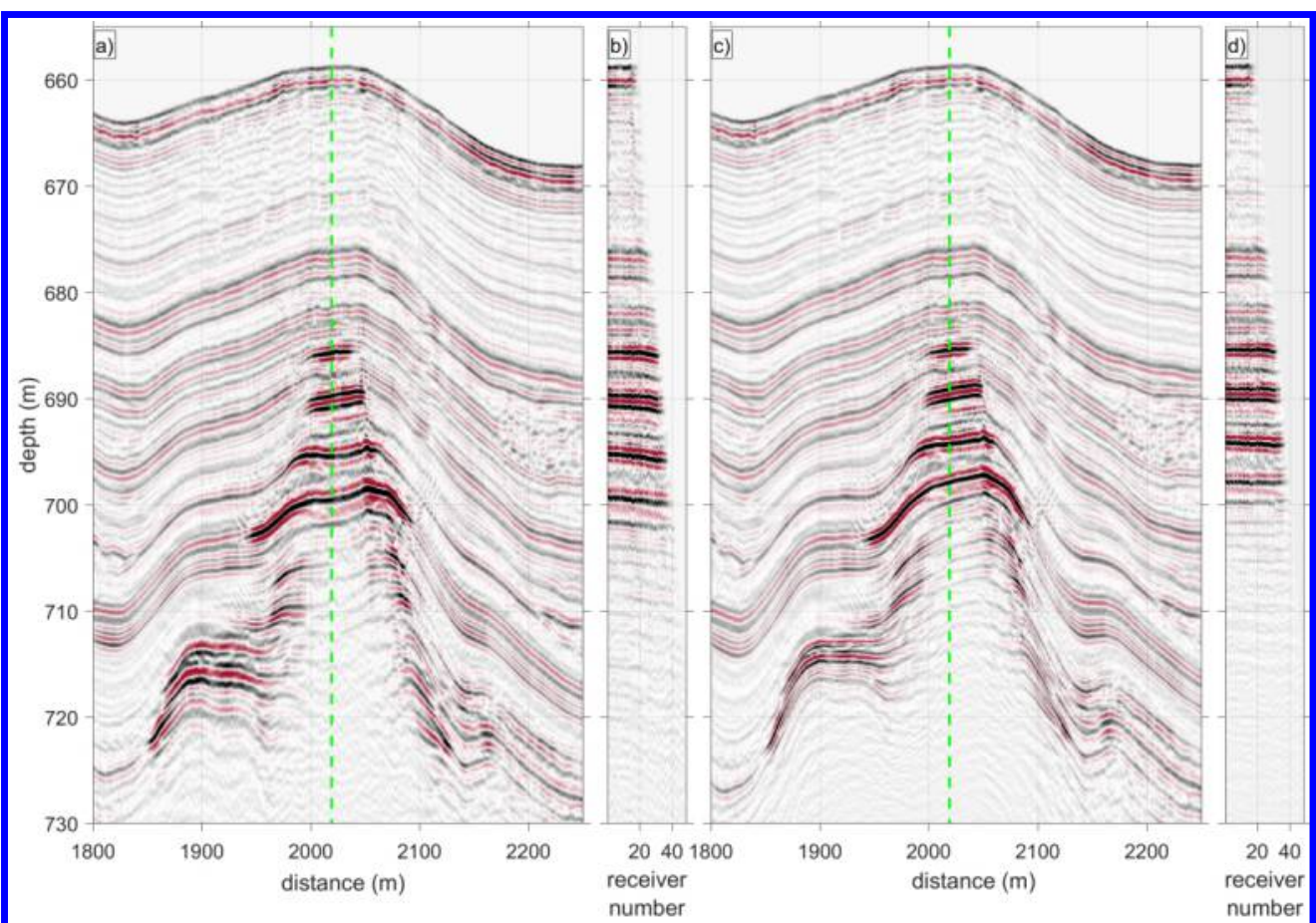

Figure 11 - (a) Sub-profile PL03PR06a, PSDM migrated. using a constant seawater velocity model. (c) is that same profile migrated using the variable velocity model presented in Figure 9b (vertical exaggeration: 10.0).

(b) and (d) show the same CMP located at the center of the anticline structure, marked by the green line, migrated at constant velocity and with the velocity model (respectively). 


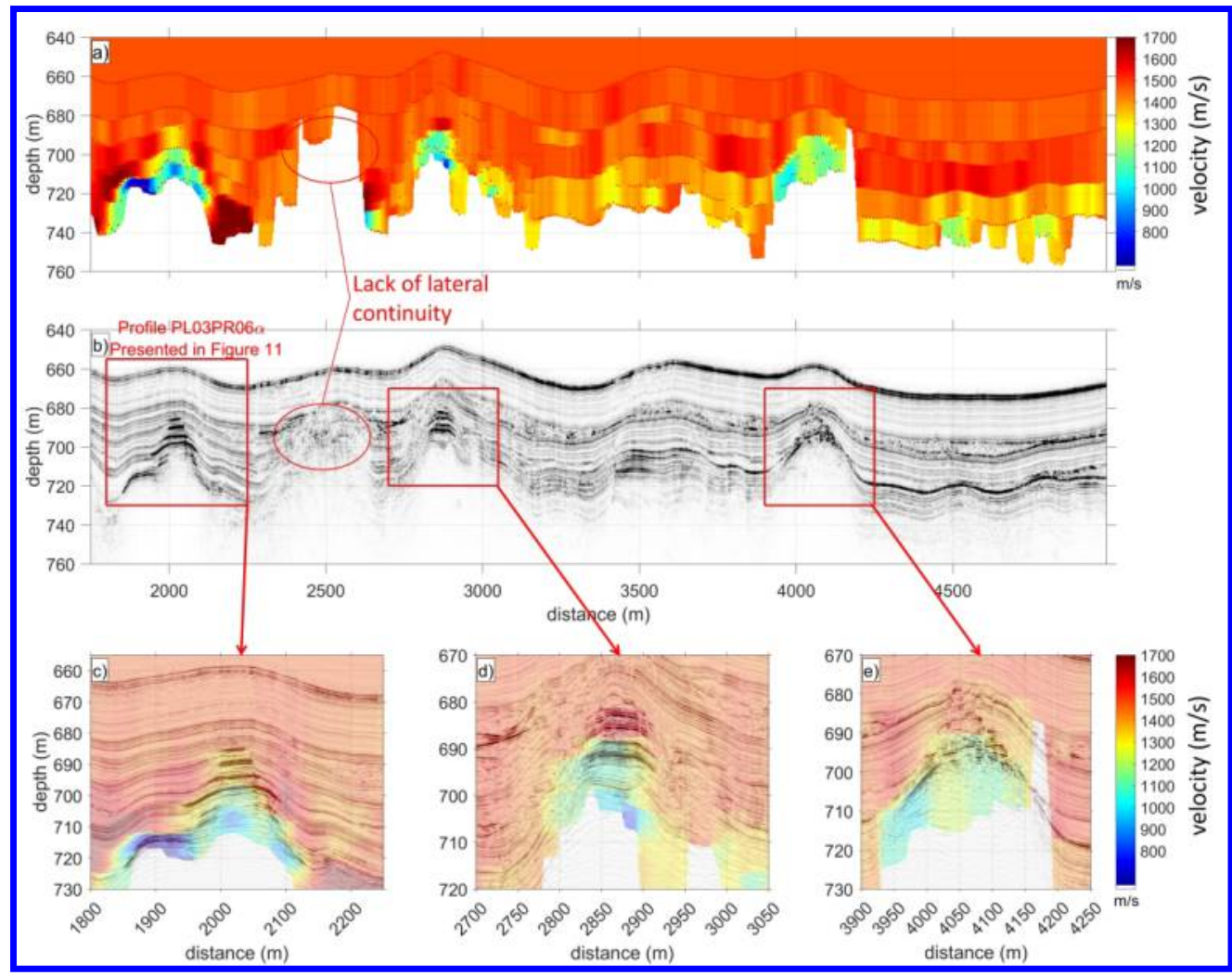

Figure 12 - Profile PL03PR06 $\beta$. (a) shows the interval velocity structures. (b) displays the seismic profile migrated using the velocity model presented in (a) (vertical exaggeration: 6.25). 
DATA AND MATERIALS AVAILABILITY

Data associated with this research are available and can be obtained by contacting the corresponding author. 